\title{
Moderate transmission but high prevalence of malaria in Madagascar
}

\author{
Vincent Robert ${ }^{\mathrm{a}, \mathrm{b}, \mathrm{c}, *}$, Gilbert Le Goff ${ }^{\mathrm{a}, \mathrm{b}}$, Lala Andrianaivolambo ${ }^{\mathrm{b}}$, Fara M. Randimby ${ }^{\mathrm{b}}$, \\ Olivier Domarle ${ }^{\mathrm{b}}$, Milijaona Randrianarivelojosia ${ }^{\mathrm{b}}$, Vaomalala Raharimanga ${ }^{\mathrm{b}}$, \\ Andrianirina Raveloson ${ }^{\mathrm{d}}$, Charles Ravaonjanahary ${ }^{\mathrm{d}}$, Frédéric Ariey ${ }^{\mathrm{b}}$ \\ a Institut de Recherche pour le Développement, Antananarivo, Madagascar \\ ${ }^{\mathrm{b}}$ Groupe de Recherche sur le Paludisme, Institut Pasteur de Madagascar, Madagascar \\ ${ }^{c}$ Muséum National d'Histoire Naturelle, USM 504, Paris, France \\ ${ }^{\mathrm{d}}$ Ministry of Health, Antananarivo, Madagascar
}

Received 29 April 2006; received in revised form 3 June 2006; accepted 5 June 2006

\begin{abstract}
Malaria transmission remains poorly documented in areas of low transmission. A study has been carried out over two consecutive years in Analamiranga, a village located at an altitude of $885 \mathrm{~m}$ on the western edge of the Malagasy highlands, with the aim of generating and updating malariometric indexes for both mosquitoes and schoolchildren. In this village, no vector control measures were performed during the study period nor during previous decades. Mosquitoes were collected monthly when landing on human volunteers and in various resting-places. Blood samples were taken every 3 months from schoolchildren aged 6-12 years and microscopically examined. Of 7,480 mosquitoes collected on human subjects, 5,790 were anophelines. Ten anopheline species were represented and three of these, Anopheles funestus, Anopheles arabiensis and Anopheles mascarensis, accounted for $59.2 \%$ of the collection. Of these three species 4,640 were also collected in resting places. The proportion of mosquitoes fed on bovids was high; conversely, the anthropophilic rate (mosquitoes fed on human beings) was especially low: $31 \%, 7 \%$ and $1 \%$, respectively, for $A$. funestus, A. arabiensis and A. mascarensis. The only confirmed malaria vector was A. funestus with a low sporozoite index (of 6,830 A. funestus, five were positive for Plasmodium falciparum and four for Plasmodium vivax). The annual entomological inoculation rate (number of bites of infected anophelines per adult person) was estimated at 2.49 with low variation over the 2 years. Overall, 909 thick blood smears were tested from blood samples taken from schoolchildren with $30.3 \%$ being malaria-positive. The four Plasmodium species infecting human subjects were detected in the following proportions: P. falciparum $78.9 \%$, P. vivax $19.4 \%$, Plasmodium malariae $1.0 \%$ and Plasmodium ovale $0.7 \%$. The proportions of children who were infected with any Plasmodium ranged from 10.7\% in February to $51.0 \%$ in September. Parasitemic children with fever (axillary temperature $>37.5^{\circ} \mathrm{C}$ ) accounted for $16.4 \%$ of the children sampled. This study demonstrates that there are substantial parasitological consequences of even a relatively low entomological transmission and also recommends including exterior resting-places of mosquitoes in future spraying campaigns in the highlands of Madagascar.
\end{abstract}

(C) 2006 Australian Society for Parasitology Inc. Published by Elsevier Ltd. All rights reserved.

Keywords: Malaria transmission; Plasmodium falciparum; Plasmodium vivax; Anopheles funestus; Anopheles arabiensis; Schoolchildren; Prevalence; Highlands

\section{Introduction}

In Madagascar, malaria remains a leading cause of morbidity and mortality. The intensity of malaria transmission varies according to the geographical areas of the island

\footnotetext{
${ }^{*}$ Corresponding author. Tel.: +331407935 13; fax: +33140351713.

E-mail address: v.robert@mnhn.fr (V. Robert).
}

(Mouchet et al., 2004). The eastern and western coastal regions are characterised by hyperendemic malaria with a transmission season of more than 6 months per year. In the central highlands, the sporogonic development of the parasite in the mosquito vector is strongly influenced by temperature, which varies according to altitude. Malaria is considered stable up to an altitude of $1,000 \mathrm{~m}$, unstable with seasonal transmission from November to May 
between 1,000 and 1,500 $\mathrm{m}$ and rare or absent over 1,500 $\mathrm{m}$ (Mouchet et al., 1993). The four plasmodial species known to infect humans are observed in Madagascar. In the highlands, the main vector is Anopheles funestus, with lower endophily and anthropophily than in mainland Africa; Anopheles arabiensis and Anopheles mascarensis, which are zoophylic, are secondary vectors (Grejbine, 1966; Fontenille et al., 1990; Marrama et al., 1995; Laventure et al., 1996; Brutus et al., 2001; Le Goff et al., 2003; Leong Pock Tsy et al., 2003; Rajaonarivelo et al., 2004). The role of rice fields as breeding places for these anophelines has already been established in the highlands of Madagascar (Marrama et al., 1995; Laventure et al., 1996; Robert et al., 2002).

The national malaria control campaigns carried out in the 1950s and 1960s were successful and led to the disappearance of $A$. funestus from the central highlands (Fontenille and Rakotoarivony, 1988). When antivectorial measures stopped, A. funestus progressively recolonised the central highlands and from 1985 to 1990 the Madagascar highlands underwent an epidemic of falciparum malaria, which caused the deaths of 40,000 inhabitants according to the Ministry of Health (Lepers et al., 1991; Blanchy et al., 1993; Mouchet et al., 1997).

House spraying with dichloro-diphenyl-trichloromethane (DDT) was performed annually by the Ministry of Health in these highlands, between altitudes of 1,000 and $1,500 \mathrm{~m}$, from 1993 to 1998 (Romi et al., 2002). From 1999 until 2005 these general campaigns were replaced by more selective operations in restricted areas of the western part of the highlands. Pyrethroid insecticides have replaced DDT since 2005.

Malaria transmission remains poorly documented in Madagascar. This study was carried out to document the malaria parasites manifested in both mosquitoes and schoolchildren. The present article describes results obtained for a period of two consecutive years in a village typical of the western edge of the Malagasy highlands. In this village, no vector control measures were performed during the study period nor during the three previous decades. This provided an opportunity to document the natural history of human malaria, bearing in mind that what is observed constitutes a baseline in the absence of implemented antivectorial measures. This combined entomological and parasitological study demonstrates that there are substantial parasitological consequences of even a relatively low entomological transmission. It also emphasises the need for an accurate programme of entomological and parasitological surveillance in the Malagasy highlands where dramatic pluri-annual malaria epidemics already occur, placing a heavy burden on public health and public health services.

\section{Materials and methods}

\subsection{Study site}

The central Malagasy highlands represent about $20 \%$ of the whole of Madagascar. They constitute an area located at more than $800 \mathrm{~m}$ above sea level with high human density in the provinces of Antananarivo and Fianarantsoa. The climate is tropical, at altitude, with two contrasting seasons. The dry season covers 6 months, from May to October, with relatively low temperatures. The rainy season, which lasts from November to April, with maximum rainfall in February, is unique to this area, because one long and one short rainy season with a short dry season in between is more typical for tropical Africa.

The study was carried out from October, 2002 to September, 2004 in Analamiranga, a village at the western edge of the Malagasy highlands in the commune of Maroharona, district of Tsiroanomandidy, province of Antananarivo, Madagascar. This village is located $2 \mathrm{~km}$ from the western bank of the Sakay River, $134 \mathrm{~km}$ directly west of Antananarivo, and $18 \mathrm{~km}$ south-west of Mahasolo. The nearest tarred road is the Antananarivo-Tsiroanomandidy axis, $45 \mathrm{~km}$ away by hard-packed track, which is in especially poor condition during the rainy season. The village is located at an altitude of $885 \mathrm{~m}$, at $19^{\circ} 14^{\prime} 35^{\prime \prime} \mathrm{S}$, $46^{\circ} 16^{\prime} 22^{\prime \prime} \mathrm{E}$. The mean annual rainfall is $1,500 \mathrm{~mm}$, with less than $20 \mathrm{~mm}$ in the dry season. The mean annual temperature is $23{ }^{\circ} \mathrm{C}$ and the mean temperature of the coldest months, July and August, ranges between 16 and $19^{\circ} \mathrm{C}$. The village is on the top of a small hill, surrounded by small valleys which have been developed into rice fields. Two rounds of rice production occur, with crops in April to May during the rainy season and in December to January, the dry season, when irrigation is required. However, the latter represents only $2 \%$ of local rice production.

The village has 900 inhabitants. Most are farmers with rice as their main activity/resource and maize, manioc and peanuts as their secondary crop. The habitat is composed of 158 houses that are made of bricks or cob and are either on one level or have one upper floor ( $50 \%$ each), with roofs which are covered with thatch (91\% of houses), tiles or sheet metal. Most inhabitants do not use any special measures to protect themselves from mosquito bites. Only three couples stated that they slept under mosquito nets. The village also has 390 zebus that spend the night in several enclosures spread throughout the village or at its nearby periphery. Other domestic animals, such as pigs, dogs, cats and poultry, are also found in the village.

\subsection{Entomological study}

The entomological study was conducted each month without interruption, with two well-tried methods. The first method involved all-night human landing catches with volunteers staying indoors or outdoors (WHO, 1992). Female mosquitoes, which are supposed to be aggressive towards human subjects, were collected as they landed on the bare legs of volunteers who simultaneously acted as bait and trappers. Two teams of eight volunteers worked from 18:00 to $06: 00 \mathrm{~h}$, each team on duty for six consecutive hours, with a changeover at midnight. These collections were performed over two consecutive nights each month. 
Four houses plus four outdoor sites within the village were used the first night and four other houses plus four other outdoor sites were used the second night. The total of human-nights was 384 for the whole study.

The second method involved the collection of resting mosquitoes. Endophilic resting mosquitoes were collected mornings from 10 bedrooms where the sheets had been sprayed with non-remanent pyrethroid insecticide. The total of bedrooms was 240 for the whole study. Exophilic resting mosquitoes were collected in three to five Muirhead-Thomson pit shelters examined early after sunrise (Muirhead-Thomson, 1958) and in various resting places such as animal shelters and cart sheds, examined early after sunrise. Any exophilic mosquitoes that were found were drawn up with a sucking tube. Ninety-four pits and a non-registered number of other resting places were visited during the whole study.

Diagnosis of anopheline mosquitoes was performed using the determination keys of Gillies and Coetzee (1987) and Grejbine (1966). Mosquitoes from the Anopheles gambiae complex were determined using PCR (Scott et al., 1993). Since A. funestus, A. arabiensis and A. mascarensis are the only known mosquitoes to be potential vectors of malaria in this area, these species were examined for parity, anthropophily and infectivity. Parity was estimated using the technique based on microscopic observation for the degree of tracheolar coiling, immediately after collection (Detinova, 1962). Anthropophily was estimated using blood-fed resting mosquitoes. Abdomens were squashed on filter paper, then dried and conserved at $4{ }^{\circ} \mathrm{C}$ with silica gel. Blood spots were tested with an ELISA with several antibodies specific for primate, bovid, pig and dog (Beier et al., 1988b). Infectivity was estimated using the head and thorax, kept individually in waterproof vials containing silica gel and placed at $-20^{\circ} \mathrm{C}$. The head and thorax were tested by an ELISA-CSP (Circum Sprorozoite Protein) to detect the presence of a plasmodial infection and, in a second step, the species Plasmodium falciparum, Plasmodium malariae or Plasmodium vivax (Beier et al., 1988a; Wirtz et al., 1987).

The daily biting rate was calculated as the ratio of the number of mosquitoes caught landing on human subjects to the number of human-nights. The endophagic rate was estimated from mosquitoes sampled by human landing collection (indoor/indoor + outdoor). Anthropophily and percentage of zebu blood-fed mosquitoes were estimated from samples of resting mosquitoes. The endophilic rate was calculated as the ratio of the mean number of female mosquitoes fed with human blood to the mean endophilic density in the same houses on the same days. Since dwellers spend all nights in their houses, the entomological inoculation rate was calculated from the product of the indoor human biting rate and the mean infectivity of anopheline vectors. The daily survival rate $(p)$ was calculated from the 2.5th root of the parous rate (based on a trophogonic cycle of 2.5 days). The malaria stability index $(s)$ was calculated as $a /-\operatorname{Ln} p$ (with $a=$ daily biting rate $=$ anthro- pophily/trophogonic cycle of 2.5 days) (Macdonald, 1957). The vectorial capacity (C) was calculated as $m a^{2} p^{n} /-\operatorname{Ln} p$ (with $m a=$ biting rate per human and with a duration of sporogonic development ( $n$ ) of 15 days) (Garret-Jones and Shidrawi, 1969).

\subsection{Schoolchildren study}

In the village, the two primary schools, Ecole Primaire Publique and Sainte Thérèse, were visited every 3 months. The Malagasy Health and Education Authorities approved the entire protocol. Informed consent for the participation of the schoolchildren was obtained from their legal guardians. Surveys were performed in October 2002, January, May, September and December 2003 and in March, May and September 2004. In classes $11^{\text {ème }}$ to $8^{\text {ème }}$, any child present at school was questioned for symptoms related to malaria. If the presence of malaria was suspected, the child was treated in agreement with the national health policy. Axillary temperature and weight were systematically recorded. A drop of blood was collected from the fingertip and blood smears were prepared. Thick smears were Giemsa-stained and microscopically examined by experienced microscopists at the Institut Pasteur de Madagascar. Thick blood film readings were standardized and quality control was performed. Parasite densities were determined by counting the number of asexual parasites per 200 white blood cells (WBCs) or per $500 \mathrm{WBCs}$ if the count was less than 10 parasites/200 WBCs, assuming a WBC count of $8,000 / \mu 1$. Thus, a sensitivity threshold was estimated at one parasite per $0.125 / \mu 1$ or eight parasites $/ \mu 1$. The proportion of people who are infected with any Plasmodium was expressed as the total parasite ratio. Fever was defined as an axillary temperature $\geqslant 37^{\circ} \mathrm{C}$.

\subsection{Statistical analysis}

Qualitative data were compared between groups using Fisher's Exact Test. Quantitative means were compared using the non-parametric Mann-Whitney $U$ test. $P$ values $<0.05$ were considered to be statistically significant.

\section{Results}

\subsection{Mosquitoes and malaria transmission}

Using human landing catches, 7,480 mosquitoes were collected and the anopheline was the most abundant mosquito collected with 5,790 (77.4\%) as against 1,359 Culex (18.2\%), 33 Aedes (0.4\%), 294 Mansonia (3.9\%) and four Coquilletidia $(0.5 \%)$. Table 1 provides data for these mosquitoes by species. Three species of Anopheles already established as potential malaria vectors accounted for $59.2 \%$ of the collection: A. funestus, A. arabiensis and A. mascarensis. Using the method for collection of resting mosquitoes, 4,640 of these three anopheline species were collected (Table 2). 
Table 1

Mosquitoes collected by human landings, with human subjects placed indoors or outdoors, in the village Analamiranga, Madagascar

\begin{tabular}{|c|c|c|c|c|c|}
\hline \multirow[t]{2}{*}{ Species } & \multicolumn{2}{|l|}{ Year 1} & \multicolumn{2}{|l|}{ Year 2} & \multirow[t]{2}{*}{ Total } \\
\hline & Indoor & Outdoor & Indoor & Outdoor & \\
\hline Anopheles funestus & 492 & 1,264 & 503 & 946 & 3,205 \\
\hline Anopheles arabiensis & 23 & 115 & 18 & 95 & 251 \\
\hline Anopheles mascarensis & 30 & 579 & 23 & 344 & 976 \\
\hline Anopheles coustani & 51 & 552 & 28 & 365 & 996 \\
\hline Anopheles squamosus-cydippis & 10 & 63 & 13 & 85 & 171 \\
\hline Anopheles rufipes & 1 & 13 & 2 & 15 & 31 \\
\hline Anopheles maculipalpis & 3 & 84 & 7 & 33 & 127 \\
\hline Anopheles pharoensis & 0 & 3 & 0 & 1 & 4 \\
\hline Anopheles flavicosta & 1 & 6 & 2 & 8 & 17 \\
\hline Anopheles pretoriensis & 2 & 6 & 1 & 3 & 12 \\
\hline Culex antennatus & 69 & 356 & 47 & 274 & 746 \\
\hline Culex univittatus/neavei & 14 & 54 & 6 & 38 & 112 \\
\hline Culex quinquefasciatus & 60 & 110 & 34 & 137 & 341 \\
\hline Culex decens & 3 & 26 & 0 & 12 & 41 \\
\hline Culex bitaeniorhynchus & 0 & 3 & 0 & 0 & 3 \\
\hline Culex tritaeniorhynchus & 0 & 1 & 0 & 0 & 1 \\
\hline Culex sitiens & 0 & 4 & 1 & 3 & 8 \\
\hline Culex giganteus & 6 & 57 & 4 & 37 & 104 \\
\hline Culex poicilipes & 0 & 3 & 0 & 0 & 3 \\
\hline Aedes albopictus & 1 & 2 & 0 & 0 & 3 \\
\hline Aedes tiptoni & 3 & 7 & 0 & 0 & 10 \\
\hline Aedes aegypti & 0 & 1 & 0 & 0 & 1 \\
\hline Aedes fowleri & 0 & 12 & 0 & 1 & 13 \\
\hline Aedes vittatus & 1 & 1 & 2 & 2 & 6 \\
\hline Aedes circumluteolus & 0 & 0 & 0 & 0 & 0 \\
\hline Mansonia uniformis & 29 & 181 & 17 & 67 & 294 \\
\hline Coquillettidia grandidieri & 0 & 0 & 1 & 3 & 4 \\
\hline Total & 799 & 3,503 & 709 & 2,469 & 7,480 \\
\hline
\end{tabular}

Table 2

Number of anophelines, potential vector of malaria, collected in the whole study in the village Analamiranga, Madagascar

\begin{tabular}{|c|c|c|c|c|c|c|}
\hline & $\begin{array}{l}\text { Human landing } \\
\text { indoors }\end{array}$ & $\begin{array}{l}\text { Human landing } \\
\text { outdoors }\end{array}$ & $\begin{array}{l}\text { Muirhead-Thomson's } \\
\text { pit }\end{array}$ & $\begin{array}{l}\text { Outdoor } \\
\text { resting }\end{array}$ & $\begin{array}{l}\text { Bedroom } \\
\text { resting }\end{array}$ & Total \\
\hline Anopheles funestus (\%) & $995(14.9)$ & $2,210(33.2)$ & $1,416(21.2)$ & $672(10.1)$ & $1,376(20.6)$ & $6,669(100)$ \\
\hline Anopheles arabiensis (\%) & $41(3.7)$ & $210(19.0)$ & $682(61.9)$ & $127(11.5)$ & $43(3.9)$ & $1,103(100)$ \\
\hline Anopheles mascarensis (\%) & $53(4.1)$ & $923(71.0)$ & $290(22.3)$ & $23(1.8)$ & $11(0.8)$ & $1,300(100)$ \\
\hline Total & 1,089 & 3,343 & 2,388 & 822 & 1,430 & 9,072 \\
\hline
\end{tabular}

\subsubsection{Anopheles funestus}

This was the most abundant mosquito. There was a monthly variation in indoor catches on human subjects, with an inordinate maximum in April (Fig. 1A and Supplementary Table S1), although the period of high abundance outdoors lasted much longer during the first year of the study, from January to June (Fig. 1B). Collections of resting mosquitoes showed the same pattern of monthly variation (Figs. 1C-E). Hourly variation of aggressiveness showed a maximum indoors at $0-1: 00 \mathrm{~h}$ and outdoors at 01:00-02:00 h (Fig. 2). The mean parous rate was $88.5 \%$ without a significant difference between human landing vs. resting catches (Fisher's Exact $P=0.09$ ) and human landing indoors vs. outdoors (Fisher's Exact $P=0.14$ ) (Table 3 and Supplementary Table S2). The proportion of bloodmeal taken from human subjects (i.e. anthropoph- ily) was $32.9 \%$, which is in line with a high zoophily for zebus (67.6\%); very few had taken their blood from pigs, dogs or several hosts (Table 3 and Supplementary Table S3). The endophagic rate for biting activity was $31.0 \%$ (Table 3). The endophilic rate for resting behaviour was $8.9 \%$. Nine A. funestus were ELISA-CSP positive from December to August with a mean sporozoitic index of 9/ $6,830=0.13 \%$ and with five and four positive for $P$. falciparum and P. vivax, respectively (Supplementary Table S4). With this mean sporozoitic index the annual entomological inoculation rate (number of bites of infected anophelines per adult person sleeping indoors) was estimated at 2.46 $(0.0013 \times 492 / 96 \times 365)$ during year 1 and $2.52(0.0013 \times$ $503 / 96 \times 365$ ) during year 2, i.e. 2.49 on average. The daily survival rate was 0.952 , the stability index 2.69 and the vectorial capacity 6.66 (Table 3 ). 


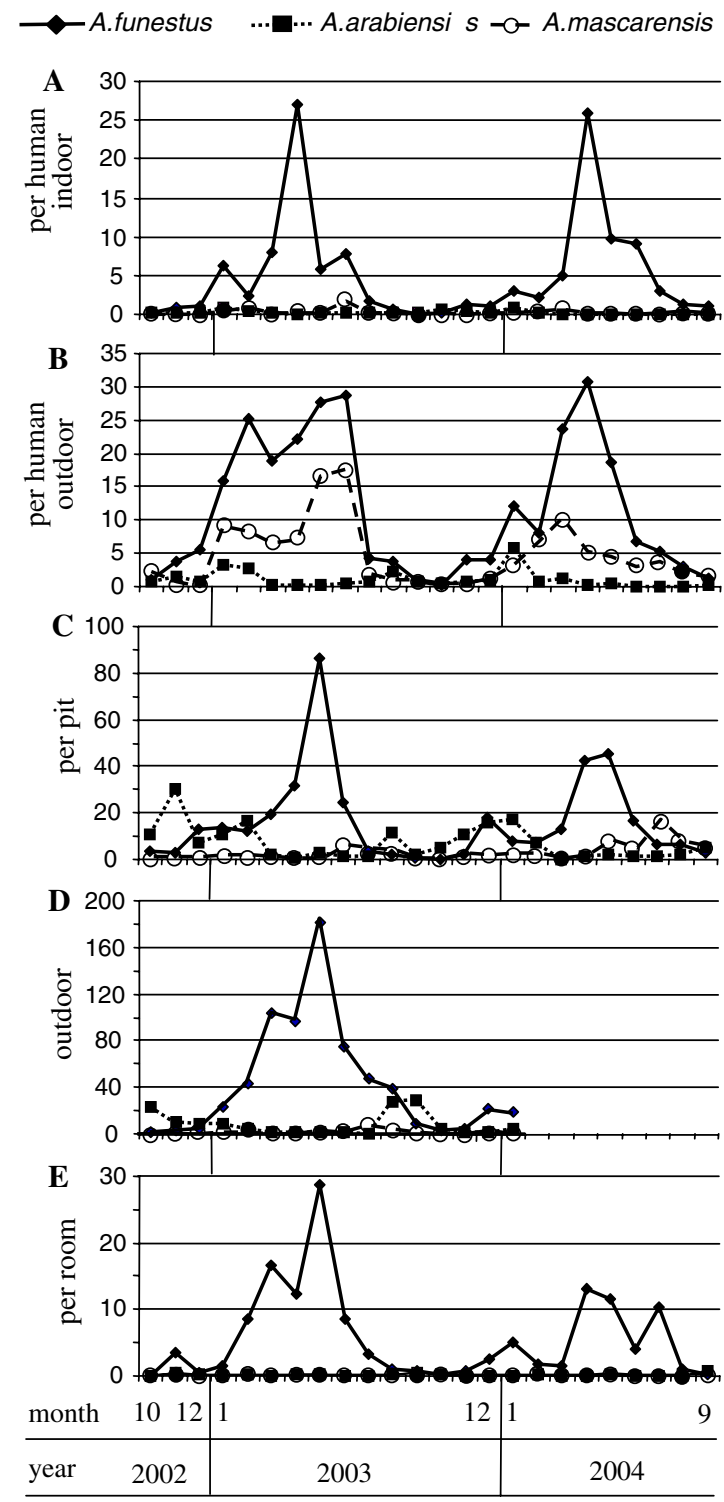

Fig. 1. Monthly variations in the densities of the anophelines, potential vectors of malaria in the village of Analamiranga, Madagascar, from October, 2002 to September, 2004 (total 9,197 mosquitoes for the three anopheline species). Results are presented: (A) per human indoors with all night human landing catches with indoor human subjects; (B) per human outdoors with all night human landing catches with outdoor human subjects; (C) per pit with Muirhead-Thomson pit shelters examined early after sunrise; (D) outdoor resting mosquitoes found in animal shelters and cart sheds, examined early after sunrise; (E) per room with pyrethrum spray catches in bedrooms, examined during the morning.

\subsubsection{Anopheles arabiensis and Anopheles mascarensis}

Mosquitoes from the A. gambiae complex were analysed to identify cryptic species. Of 264 mosquitoes sampled during the whole study with various methods of collection, all were unambiguously assigned to $A$. arabiensis. This species and $A$. mascarensis were less numerous than $A$. funestus, especially for indoor human landing catches. Maximum aggressivity indoors was observed at 22:00-23:00 $\mathrm{h}$ and outdoors at 21:00-22:00 h for A. arabiensis and at 01:0002:00 h outdoor for A. mascarensis (Fig. 2). Any parame-
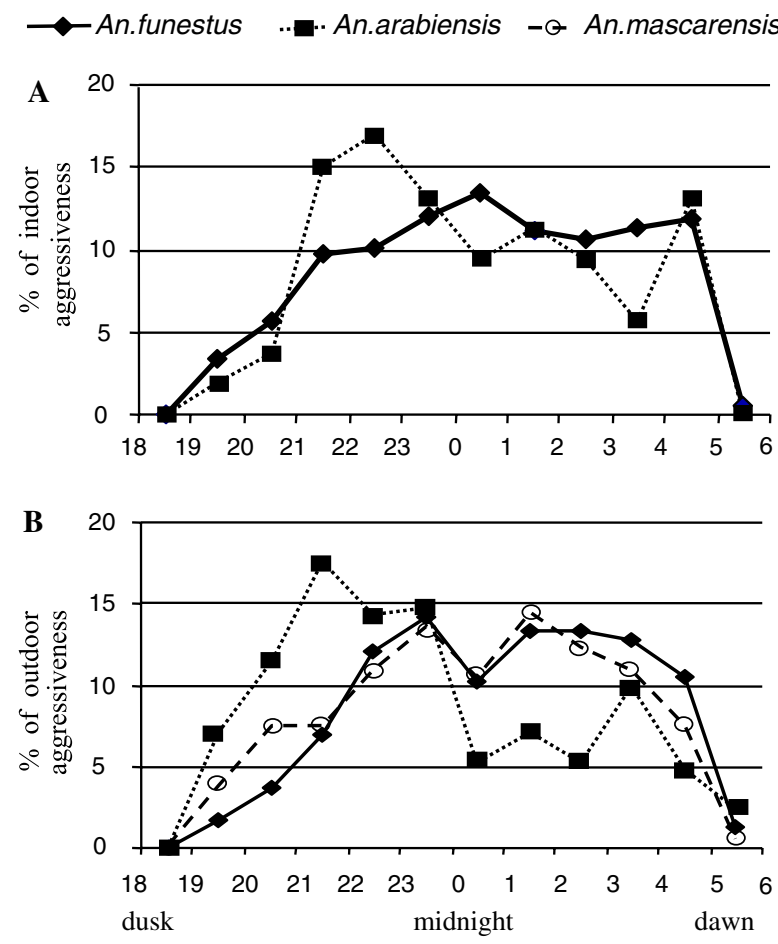

Fig. 2. Hourly variations of densities of the anopheline vectors (total 9,197 mosquitoes for the three species) presented in percentages of total aggressiveness. Results are presented: (A) with all night human landing catches indoors; (B) with all night human landing catches outdoors. The sample of indoor Anopheles mascarensis caught is too low to permit establishment of percentages.

ters in relation to their potential role in human malaria transmission were much lower than those obtained for A. funestus (Table 3). No A. arabiensis or A. mascarensis were shown to be infected with any Plasmodium.

\subsection{Schoolchildren and blood parasites}

The 909 thick smears were obtained from 473 children ranging from 6 to 12 years of age, among which $56 \%$ were involved in one cross-survey, $21 \%$ in two, and $23 \%$ in three to eight (Supplementary Table S5). Their mean axillary temperature and weight were $37.02{ }^{\circ} \mathrm{C}$ and $21.57 \mathrm{~kg}$, respectively (Supplementary Table S6).

Overall, 275 thick smears $(30.2 \%)$ presented at least one parasite belonging to the genus Plasmodium (Table 4). The four Plasmodium species infecting humans were encountered in the following proportion: $P$. falciparum $77.8 \%, P$. vivax $16.0 \%, P$. malariae $1.1 \%$ and $P$. ovale $0.4 \%$ and mixed infections $4.7 \%$, always involving $P$. falciparum (total $=$ $100.0 \%$ ). No mixed infection with more than two Plasmodium species was observed. The relative percentage of the four species was $P$. falciparum $78.8 \%, P$. vivax $19.5 \%, P$. malariae $1.0 \%$ and $P$. ovale $0.7 \%$ (total $=100.0 \%$ ). Among the 275 children with blood parasites, fever was present in 149 (54.2\%) (Supplementary Table S6). The mean temperature was $36.99^{\circ} \mathrm{C}$ in children without parasites versus $37.08^{\circ} \mathrm{C}$ in children with parasites $(P=0.21$ by the 
Mann-Whitney $U$ test). The mean temperature was $37.06{ }^{\circ} \mathrm{C}$ in children with asexual $P$. falciparum at densities lower than $1,000 / \mu \mathrm{l}$ versus $37.22^{\circ} \mathrm{C}$ at densities $\geqslant 1,000 / \mu 1$ ( $P=0.32$ by the Mann-Whitney $U$ test where $n=158$ and 60 , respectively). Children with both blood parasites and fever represented $16.4 \%$ of those present at school.

To determine if infection status (uninfected, single or mixed infections) deviates from an independent random distribution, observed versus expected frequencies of various combinations of Plasmodium species infections or assemblages were compared (Table 4). In practice, low numbers of $P$. malariae- and $P$. ovale-positive smears did not allow this examination. However, $P$. falciparum and $P$. vivax were randomly distributed, suggesting these infections appear to develop independently of one another (Fisher's Exact $P=0.63$ ) (Janovy et al., 1995).

The total parasite ratio reached a maximum in September, 2003 and May, 2004 (Table 4). The prevalence of the sexual stages of $P$. falciparum follows a pattern similar to that of the gametocytes of $P$. falciparum with, on average, a density 8.4 times higher (Fig. 3A and Supplementary Table S7). Variations in density of the asexual stages and gametocytes followed similar patterns, except in January, 2003 (Fig. 3B). For the asexual stages, a maximum in prevalence corresponds to a minimum in density and vice-versa (Figs. 3A and B); in other words, at a period of high prevalence the mean positive densities were low and at a period of low prevalence the mean densities were high.

\section{Discussion}

The bioecology of the three potential vectors of human malaria at the western edge of the Malagasy highlands, $A$. funestus, $A$. arabiensis and $A$. mascarensis demonstrated a strong tendency to exophily, both for biting and resting behaviour, and zoophily for bloodmeals. For these reasons, the vectorial capacity was low for A. funestus, and very low for $A$. arabiensis and $A$. mascarensis. According to our results, $A$. funestus is the main malaria vector. $A$. arabiensis and A. mascarensis were previously found infected in the highlands but with a minor role in malaria transmission in the presence of A. funestus as reported by different authors (Grejbine, 1966; Brutus et al., 2001; Le Goff et al., 2003; Leong Pock Tsy et al., 2003). Relatively high longevity, especially for A. mascarensis, was not sufficient in itself to allow one to draw an alternative conclusion. The zoophily of $A$. funestus is a striking feature. In the whole of continental Africa, this species appears as fully anthropophilic. One hypothetical explanation would reside in DDT house spraying campaigns performed in the Malagasy highlands that had selected for behavioural change on a genetic background including zoophily in the behavioural repertoire (Duchemin et al., 2001). Even if the village in this study has not been sprayed during recent years (see Section 1), one may speculate about the possible impact of any large insecticide campaign that occurred 
sion estimation. The transmission season for P. falciparum starts at the beginning of the rainy/hot season (DecemberJanuary) and lasts until the middle of the dry/cold season (up to August). The transmission season for $P$. vivax starts later, at the end of the rainy/hot season, but it also lasts until the middle of the dry/cold season (June in this study). The transmission for $P$. vivax appears to be more hectic from an entomological point of view than that of $P$. falciparum because zero infected mosquitoes were detected during year 2 , an observation not confirmed with parasitological data, perhaps due to the small sample size of infected mosquitoes. Among the differences between years, the lower parasite ratio in September of year 2 remains partly unexplained, but it is possible the drugs provided by the medical team for treatment in cases of suspected malaria, in agreement with the national health policy, had some effect.

The period of high transmission for $P$. falciparum starts at the beginning of the hot and rainy season. This indicates that insecticide spray campaigns should be scheduled in December, i.e. 1 or 2 months in advance of the present spraying calendar.

Infected mosquitoes (both $P$. falciparum and $P$. vivax) were collected in outside shelters, demonstrating endo-exophilic vector behaviours which negatively affect any antivectorial measures. This is important to consider for the insecticide spray campaign in the Malagasy highlands which ordinarily focuses on indoor spraying. It would be advantageous to include outside resting places suitable for mosquitoes, such as animal shelters, cart sheds and house ruins, especially during epidemic episodes in the campaign.

Finally, this study provides basic data for a typical village at the western edge of the Madagascar highlands, which highlights the huge parasitological consequences of relatively low entomological transmission. It emphasises the need for an accurate surveillance programme in the Malagasy highlands where dramatic pluri-annual malaria epidemics recently occurred. It also emphasises that no level of malaria transmission is acceptable in terms of public health.

\section{Acknowledgements}

We are grateful to the inhabitants of Analamiranga for their cooperation throughout this study and members of the technical staff of Groupe de Recherche sur le Paludisme for their assistance. Docteur Philippe Mauclère, Director of the Institut Pasteur de Madagascar during the study, is warmly thanked. This study was supported by the Ministry of Health and Family Planning of Madagascar via the World Bank project CRESAN.2 (3302MAG), by the Institut Pasteur de Madagascar, by the Grand Programme Anopheles of the Institut Pasteur, by the Programme $\mathrm{Pal}+$ of the Ministère Français de la Recherche and by the Institut de Recherche pour le Développement.

\section{Appendix A. Supplementary data}

Supplementary data associated with this article can be found, in the online version, at doi:10.1016/j.jpara.2006. 06.005 .

\section{References}

Albonico, M., De Giorgi, F., Razanakolona, J., Raveloson, A., Sabatinelli, G., Pietra, V., Modiano, D., 1999. Control of epidemic malaria in the highlands of Madagascar. Parassitologia 41, 373-376.

Beier, J.C., Killeen, G.F., Githure, J.I., 1999. Entomological inoculation rates and Plasmodium falciparum malaria prevalence in Africa. Am. J. Trop. Med. Hyg. 61, 109-113.

Beier, M.S., Schwartz, I.K., Beier, J.C., Perkins, P.V., Onyango, F., Koros, J.K., Campbell, G.H., Andrysiak, P.M., Brandling-Bennett, A.D., 1988a. Identification of malaria species by ELISA in sporozoite and oocyst infected Anopheles from western Kenya. Am. J. Trop. Med. Hyg. 39, 323-327.

Beier, J.C., Perkins, P.V., Wirtz, R.A., Koros, J., Diggs, D., Gargan II, T.P., Koech, D.K., 1988b. Bloodmeal identification by direct enzymelinked immunosorbent assay (ELISA), tested on Anopheles (Diptera:Culicidae) in Kenya. J. Med. Entomol. 25, 9-16.

Blanchy, S., Rakotonjanabelo, A., Ranaivoson, G., Rajaonarivelo, E., 1993. Epidémiologie du paludisme sur les Hautes Terres Malgaches depuis 1978. Cahiers Santé 3, 155-161.

Boisier, P., Jambou, R., Raharimalala, L., Roux, J., 2002. Relationship between parasite density and fever risk in a community exposed to a low level of malaria transmission in Madagascar highlands. Am. J. Trop. Med. Hyg. 67, 137-140.

Brutus, L., Le Goff, G., Rasoloniaina, L.G., Rajaonarivelo, V., Raveloson, A., Cot, M., 2001. Lutte contre le paludisme dans le Moyen-Ouest de Madagascar: comparaison de l'efficacité de la lambda-cyhalothrin $\mathrm{du}$ DDT en aspersions intra-domiciliaires. I - Etude entomologique. Parasite 8, 297-308.

Carnevale, P., Frezil, J.L., Bosseno, M.F., Le Pont, F., Lancien, L., 1978. Etude de l'agressivité d'Anopheles gambiae A en fonction de l'âge et du sexe des sujets humains. Bull. Org. Mond. Santé 56, 147-154.

Cot, M., Brutus, L., Le Goff, G., Rajaonarivelo, V., Raveloson, A., 2001. Lutte contre le paludisme dans le Moyen-Ouest de Madagascar: comparaison de l'efficacité de la lambda-cyhalothrin du DDT en aspersions intra-domiciliaires. II - Etude parasitologique et clinique. Parasite 8, 309-316.

Detinova, T.S., 1962. Age-grouping methods in Diptera of medical importance. WHO. Mon. 47.

Duchemin, J.B., Leong Pock Tsy, J.M., Rabarison, P., Roux, J., Coluzzi, M., Costantini, C., 2001. Zoophily of Anopheles arabiensis and A. gambiae in Madagascar demonstrated by odour-baited entry traps. Med. Vet. Entomol. 15, 50-57.

Fontenille, D., Lepers, J.P., Campbell, G.H., Coluzzi, M., Rakotoarivony, I., Coulanges, P., 1990. Malaria transmission and vector biology in Manarintsoa, high plateaux of Madagascar. Am. J. Trop. Med. Hyg. 43, 107-115.

Fontenille, D., Rakotoarivony, I., 1988. Reappearance of Anopheles funestus as a malaria vector in Antananarivo region, Madagascar. Trans. R. Soc. Trop. Med. Hyg. 82, 644-645.

Garret-Jones, C., Shidrawi, G.R., 1969. Malaria vectorial capacity of a population of Anopheles gambiae; an exercise in epidemiological entomology. Bull. World Health Organ. 40, 531-545.

Gillies, M.T., Coetzee, M., 1987. A supplement to the Anophaelinae of Africa South of the Sahara. Publication of the South African Institute for Medical Research, $\mathrm{N}^{\circ} 55$, p. 143.

Grejbine, A., 1996. Insectes Diptères Culicidae Anophelinae. Faune de Madagascar Tome XXII, ORSTOM CNRS (Ed.), Paris, p. 487 . 
Groupe de Recherche sur le Paludisme/IPM, 2002. Atlas évolutif du paludisme à Madagascar. Institut Pasteur de Madagascar (Ed.), Antananarivo, p. 33.

Hay, S.I., Guerra, C.A., Tatem, A.J., Atkinson, P.M., Snow, R.W., 2005. Urbanization, malaria transmission and disease burden in Africa. Nat. Rev. Microbiol. 3, 81-90.

Jambou, R., Ranaivo, L., Raharimalala, L., Randrianaivo, J., Rakotomanana, F., Modiano, D., Pietra, V., Boisier, P., Rabarijaona, L., Rabe, T., Raveloson, N., de Giorgi, F., 2001. Malaria in the highlands of Madagascar after five years of indoor house spraying of DDT. Trans. R. Soc. Trop. Med. Hyg. 95, 14-18.

Janovy Jr., J., Clopton, R.E., Clopton, D.A., Snyder, S.D., Efting, A., Krebs, L., 1995. Species density distributions as null models for ecologically significant interactions of parasite species in an assemblage. Ecol. Model. 77, 189-196.

Laventure, S., Mouchet, J., Blanchy, S., Marrama, L., Rabarison, P., Andrianaivolambo, L., Rajaonarivelo, E., Rakotoarivony, I., Roux, J., 1996. Le riz: source de vie et de mort sur le plateaux de Madagascar. Cahiers Santé 6, 79-86.

Le Goff, G., Randimby, F.M., Rajaonarivelo, V., Laganier, R., Leong Pock Tsy, J.M., Ceianu, C.S., Duchemin, J.B., Robert, V., 2003. Anopheles mascarensis de Meillon 1947, vecteur de paludisme dans le Moyen-Ouest de Madagascar? Arch. Inst. Pasteur Madagascar 69, 57-62.

Leong Pock Tsy, J.M., Duchemin, J.B., Marrama, L., Rabarison, P., Le Goff, G., Rajaonarivelo, V., Robert, V., 2003. Distribution of the species of the Anopheles gambiae complex, and first evidences of A. merus as malaria vector in Madagascar. Malaria J. 2, 33.

Lepers, J.P., Fontenille, D., Rason, M.D., Chougnet, C., Astagneau, P., Coulanges, P., Deloron, P., 1991. Transmission and epidemiology of newly transmitted falciparum malaria in the central highland plateaux of Madagascar. Ann. Trop. Med. Parasitol. 85, 297-304.

Macdonald, G., 1957. The epidemiology and control of malaria. Oxford Univ. Press, Oxford, $201 \mathrm{p}$.

Marrama, L., Rajaonarivelo, E., Laventure, S., Rabarison, P., 1995. Anopheles funestus et la riziculture sur les plateaux de Madagascar. Cahiers Santé 5, 415-419.

Mbogo, C.N., Snow, R.W., Khamala, C.P., Kabiru, E.W., Ouma, J.H., Githure, J.I., Marsh, K., Beier, J.C., 1995. Relationships between
Plasmodium falciparum transmission by vector populations and the incidence of severe disease at nine sites on the Kenyan coast. Am. J. Trop. Med. Hyg. 52, 201-206.

Mouchet, J., Blanchy, S., Rakotonjanabelo, A., Ranaivoson, G., Rajaonarivelo, E., Laventure, S., Rossella, M., Aknouche, F., 1993. Stratification épidémiologique du paludisme à Madagascar. Arch. Inst. Pasteur Madagascar 60, 50-59.

Mouchet, J., Carnevale, P., Coosemans, M., Julvez, J., Manguin, S., Richard-Lenoble, D., Sircouylon, J., 2004. Biodiversité du paludisme dans le monde. John Libbey Eurotext, Paris, 428 p.

Mouchet, J., Laventure, S., Blanchy, S., Fioramonti, R., Rakotonjanabelo, A., Rabarison, P., Sircoulon, J., Roux, J., 1997. La reconquête des Hautes Terres de Madagascar par le paludisme. Bull. Soc. Pathol. Exot. 90, 162-168.

Muirhead-Thomson, R.C., 1958. A pit shelter for sampling outdoor mosquito population. Bull. World Health Organ. 19, 241-261.

Rajaonarivelo, V., Le Goff, G., Cot, M., Brutus, L., 2004. Les anophèles et la transmission du paludisme à Ambohimena, village de la marge occidentale des Hautes-Terres madagaches. Parasite 11, $75-82$.

Robert, V., Le Goff, G., Ariey, F., Duchemin, J.B., 2002. A possible alternative method for collecting mosquito larvae in rice fields. Malar. J. 1, 4.

Romi, R., Razaiarimanga, M.C., Raharimanga, R., Rakotondraibe, E.M., Ranaivo, L.H., Pietra, V., Raveloson, A., Majori, G., 2002. Impact of the malaria control campaign (1993-1998) in the highlands of Madagascar: parasitological and entomological data. Am. J. Trop. Med. Hyg. 66, 2-6.

Scott, J.A., Brogdon, W.G., Collins, F.H., 1993. Identification of single specimens of the Anopheles gambiae complex by the polymerase chain reaction. Am. J. Trop. Med. Hyg. 49, 520-529.

WHO, 1992. Entomological field techniques for malaria control. World Health Organisation, Geneva.

Wirtz, R.A., Zavala, F., Charoenvit, Y., Campbell, G.H., Burkot, T.R., Schneider, I., Esser, K.M., Beaudoin, R.L., Andre, R.G., 1987. Comparative testing of monoclonal antibodies against Plasmodium falciparum sporozoites for ELISA development. Bull. World Health Organ. 65, 39-45. 